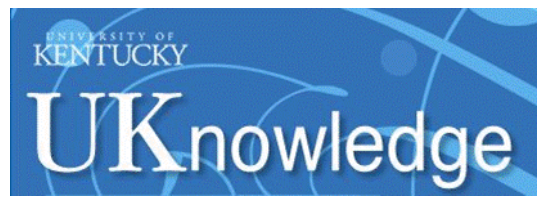

University of Kentucky

UKnowledge

\title{
Multi-Physics Modeling for Electric and Hybrid Vehicles with In- Wheel Electric Motors
}

\author{
Vandana Rallabandi \\ University of Kentucky, vandana.rallabandi@uky.edu \\ Damien Lawhorn \\ University of Kentucky, damien.lawhorn@uky.edu \\ Dan M. Ionel \\ University of Kentucky, dan.ionel@uky.edu \\ Xiao Li \\ ANSYS, Inc.
}

Follow this and additional works at: https://uknowledge.uky.edu/peik_facpub

Part of the Power and Energy Commons

Right click to open a feedback form in a new tab to let us know how this document benefits you.

\section{Repository Citation}

Rallabandi, Vandana; Lawhorn, Damien; Ionel, Dan M.; and Li, Xiao, "Multi-Physics Modeling for Electric and Hybrid Vehicles with In-Wheel Electric Motors" (2018). Power and Energy Institute of Kentucky Faculty Publications. 39.

https://uknowledge.uky.edu/peik_facpub/39

This Conference Proceeding is brought to you for free and open access by the Power and Energy Institute of Kentucky at UKnowledge. It has been accepted for inclusion in Power and Energy Institute of Kentucky Faculty Publications by an authorized administrator of UKnowledge. For more information, please contact UKnowledge@lsv.uky.edu. 


\title{
Multi-Physics Modeling for Electric and Hybrid Vehicles with In-Wheel Electric Motors
}

\author{
Digital Object Identifier (DOI) \\ https://doi.org/10.1109/ITEC.2018.8450091
}

\section{Notes/Citation Information}

Published in 2018 IEEE Transportation Electrification Conference and Expo (ITEC).

(C) 2018 IEEE Copyright Notice. "Personal use of this material is permitted. Permission from IEEE must be obtained for all other uses, in any current or future media, including reprinting/republishing this material for advertising or promotional purposes, creating new collective works, for resale or redistribution to servers or lists, or reuse of any copyrighted component of this work in other works."

The document available for download is the authors' manuscript version that is accepted for publication. The final published version is copyrighted by IEEE and will be available as: V. Rallabandi, D. Lawhorn, D.M.lonel, and X. Li "Multi-Physics Modeling for Electric and Hybrid Vehicles with In-wheel Electric Motors," Rec. 2018 IEEE Transportation Electrification Conference and Expo (ITEC), Long Beach, CA, June 2018, 6p. doi:10.1109/ITEC.2018.8450091 


\section{Multi-Physics Modeling for Electric and Hybrid Vehicles with In-wheel Electric Motors}

\author{
Vandana Rallabandi, Damien Lawhorn, Dan M. Ionel \\ SPARK Laboratory \\ University of Kentucky, Lexington, KY \\ vandana.rallabandi@uky.edu,dan.ionel@uky.edu
}

\author{
Xiao Li \\ ANSYS Inc. \\ Pittsburgh, PA \\ xiao.li@ansys.com
}

\begin{abstract}
This paper discusses multi-domain and multiphysics modeling of in-wheel electric vehicles using ANSYS Simplorer and ANSYS Maxwell. The study includes component level modeling of the vehicle, brakes, wheels, battery, traction motor, inverter, solar panels and boost converter. The traction motor used is an axial flux permanent magnet synchronous machine. In order to accommodate both the large time constants of the mechanical system and the high switching frequency power electronics, average models of the inverter and boost converter are considered. Simulation examples are provided for the University of Kentucky Gato Del Sol V car.
\end{abstract}

Index Terms - Permanent magnet synchronous machine, electric vehicles, solar panels, ANSYS Simplorer.

\section{INTRODUCTION}

Electric vehicles (EV) constitute a subject of increasing importance owing to the concern over emissions, and emphasis on smart grids. Recent literature on EV includes the development and control of electric motors [1], [2], their role in grid support including the performance of functions such as primary frequency regulation, balancing intermittant renewable energy [3]-[5] and system level modeling [6], [7], [8]. ADVISOR (ADvanced VehIcle SimulatOR), a tool, which runs in MATLAB/Simulink capable of assesing performance and fuel economy of EVs, HEVs and other vehicles was developed by the National Renewable Energy Laboratory's (NREL) Center for Transportation Technologies and Systems [9]. Other such platforms include Autonomie, capable of analyzing new powertrain configurations, advanced transmissions, engines and control strategies developed by Argonne National Labs [10].

This paper discusses the multi-domain modeling of an inwheel drive electric vehicle exemplified for a small electric car, such as the University of Kentucky solar car shown in Fig. 1b. Component level modeling of the mechanical constituents including the vehicle, wheels, brake, engine and controllers is done in the ANSYS Simplorer platform. A detailed model of the traction motor may be developed in ANSYS Maxwell. The simulation approach is illustrated for two different implementations, in the first, the vehicle is allelectric, fed by a battery driving a 3-phase permanent magnet synchronous motor (PMSM) employed for traction. In order to extend the range, plug-in hybrid implementations with onboard solar panels and maximum power point tracking are studied.

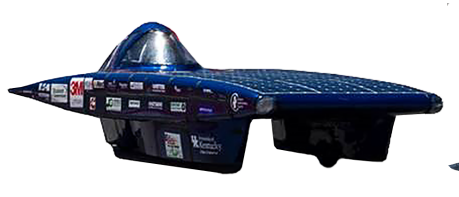

(a)

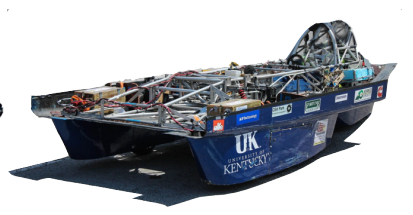

(b)

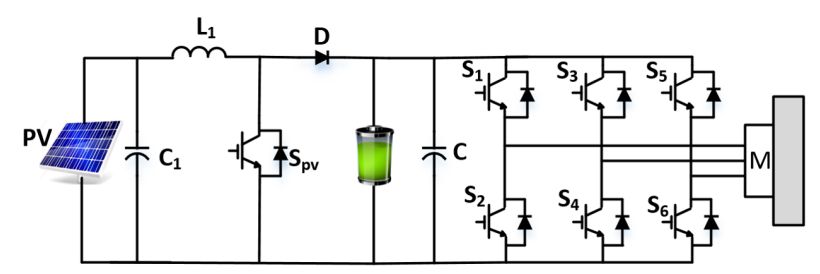

(c)

Figure 1. The UK Solar Car Gato Del Sol V with the PV equipped body cover (a) and with the cover removed (b). Photos courtesy of the UK Solar Car Team. Power system schematic for the car including the solar PV panels, the DC-DC converter for MPPT, battery, inverter and in wheel motor.

\section{Multi-Domain MOdeling}

The different components of the vehicle considered in the model of Fig. 2 include mechanical components of the car, wheel, brake, electrical components, namely, traction motor, inverter and battery. Other constituents of the system include the driver, which contains vehicle velocity controllers, and outputs signals of start, drive, stop and idle, and the EV controller, which distributes the braking functions between the mechanical system and traction motor. Braking is primarily performed by the electric machine.

The dynamic equation used in the model of the car is given as,

$$
F_{t}=m \frac{d v}{d t}+\mu m g \cos (\alpha)+\frac{1}{2} \rho C_{d} A v^{2}+m g \sin (\alpha),
$$

where, $F_{t}$ is the tractive force; $\mathrm{m}$, the mass of the vehicle; $\mathrm{v}$, the vehicle's linear velocity; $\mu$, the coefficient of rolling friction,; $\alpha$, the road angle, $A$, the frontal area; $C_{d}$, the drag coefficient, $\rho$ and the density of air. The relation between the car's velocity and wheel's rotational velocity is obtained by considering the dynamics of the wheel from the following,

$$
J \frac{d \omega_{r}}{d t}=T_{t}-F_{x} r_{w}
$$

Authors' manuscript version. The final, published version is copyrighted by IEEE and is available as: V. Rallabandi, D. Lawhorn, and D. M. Ionel, "Multi-Physics Modeling for Electric and Hybrid Vehicles with In-wheel Electric Motors," Rec. 2018 IEEE Transportation Electrification Conference and Expo (ITEC), Long Beach, CA, June 2018, 6p. doi:10.1109/ITEC.2018.8450091 (O2018 IEEE Copyright Notice. "Personal use of this material is permitted. Permission from IEEE must be obtained for all other uses, in any current or future media, including reprinting/republishing this material for advertising or promotional purposes, creating new collective works, for resale or redistribution to servers or lists, or reuse of any copyrighted component of this work in other works." 


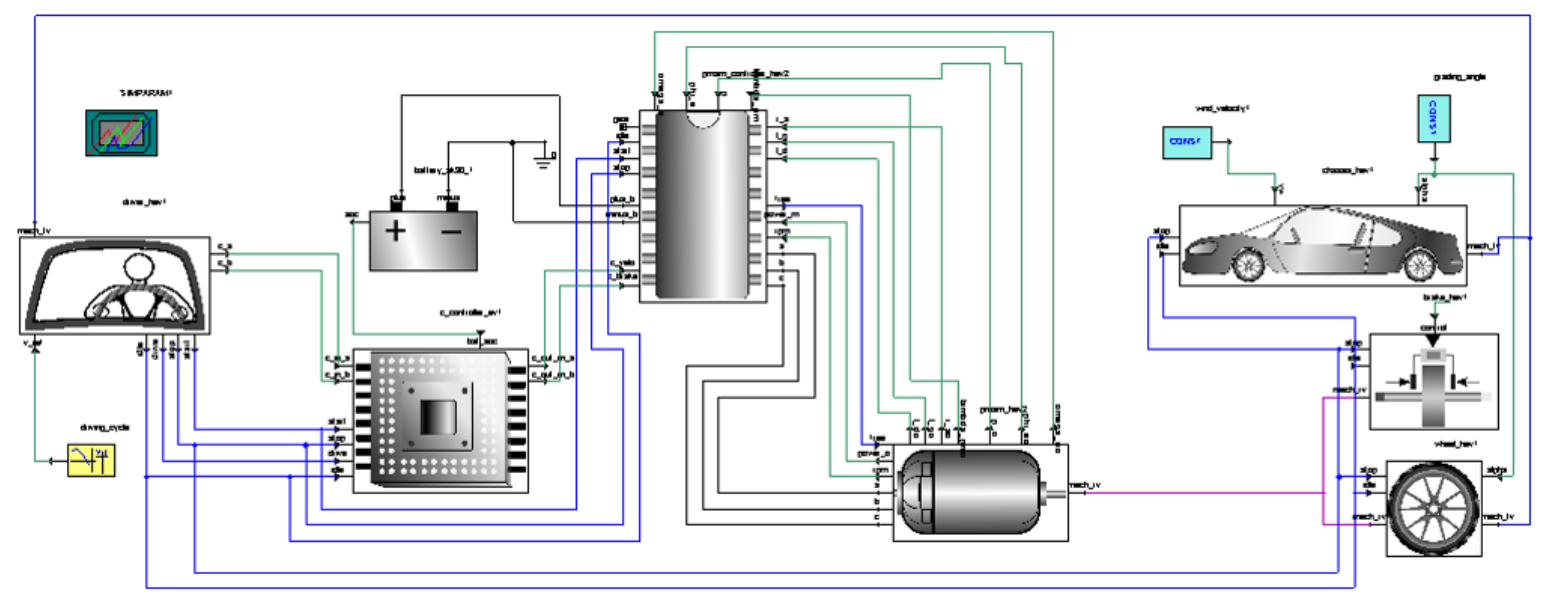

Figure 2. An all-electric vehicle model in the ANSYS Simplorer system simulator including the driver, EV controller, battery, traction motor and drive, car, brake and wheel. The permanent magnet synchronous motor (PMSM) drive incorporates the power electronic inverter and the associated controls.

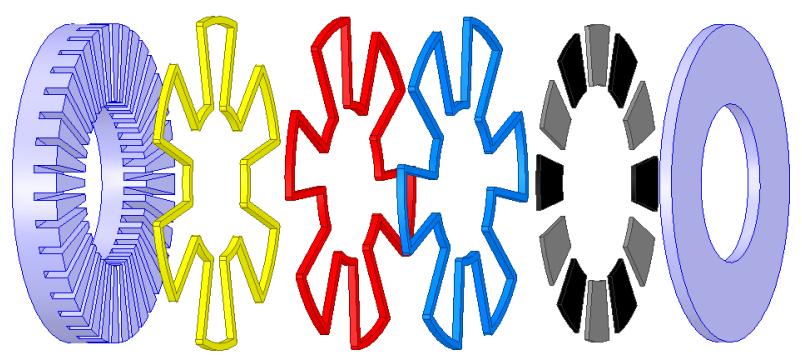

(a)

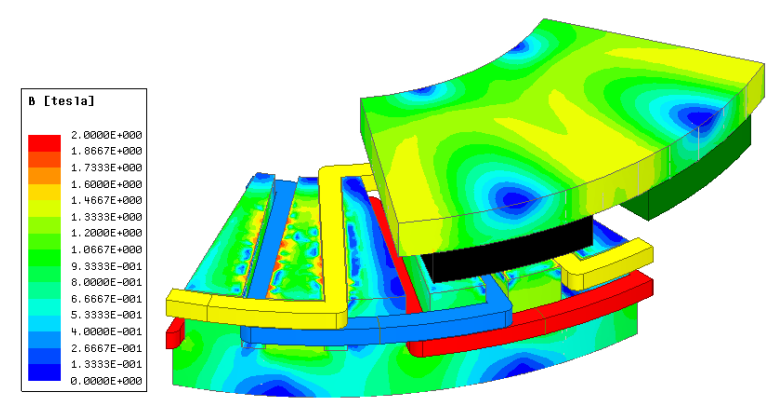

(b)

Figure 3. (a) The 3D FEA model of the traction motor, an axial flux two rotor, single stator PMSM employed in the UK solar car. (b) Flux plots as obtained from ANSYS Maxwell.

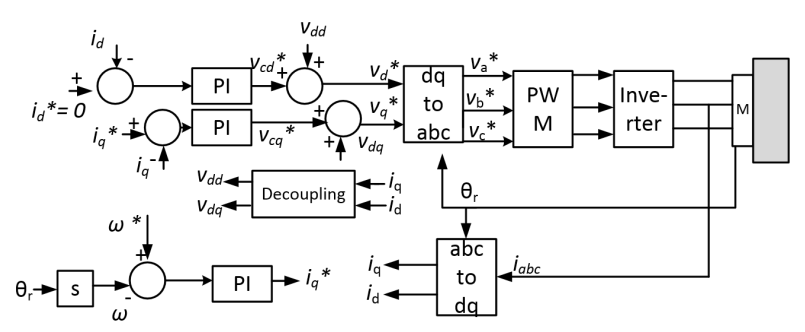

Figure 4. Vector control for the permanent magnet synchronous machine. The d-axis component of the current, oriented along the rotor magnetic field, is maintained at zero. where, $J$ is the moment of inertia of the wheel; $\omega_{r}$, the wheel's angular velocity; $T_{t}$, the traction torque; $F_{x}$, the wheel longitudinal reaction force, and $r_{w}$, the wheel radius. For non driven wheels, the term $T_{t}$ may be set to zero. The longitudinal wheel reaction force is found from the slip ratio and fitted wheel constants. The wheel slip ratio is given as

$$
\lambda=\frac{r_{w} \omega_{r}-v}{r_{w} \omega_{r}} .
$$

The wheel's friction coefficient is a function of slip, and is obtained from a model such as the commonly used Pacejka Tire Model [11]. The longitudinal force is the product of the normal wheel force, which is a function of vehicle mass, geometric parameters, grading angle, and acceleration and the coefficient of friction.

The brake component is based on a single state hydraulic model. Regenerative braking is the major braking source. The electric vehicle seen in Fig. 2 employs as traction motor, an axial flux permanent magnet synchronous motor with a single stator and rotor, and an exploded view is seen in (Fig. 3a). A detailed 3D electromagnetic model for this motor which takes into account non-linearity, saturation and electromagnetic behavior can be developed in ANSYS Maxwell (Fig. 3b) and is exemplified in [12]. The large time constants associated with the mechanical system necessitate long simulation times. However, power electronics converters switch in the order of $\mathrm{kHz}$, and require small time steps. This motivates the use of average models, such as the ones expemplified in [13], [14], for the inverter. The PMSM controller, which employs vector control (Fig. 4) calculates the reference torque based on the set speed. The current required to produce this torque is calculated as follows,

$$
\begin{aligned}
T_{e} & =K_{p}\left(w_{m}^{*}-w_{m}\right)+K_{i}\left(w_{m}^{*}-w_{m}\right), \\
i_{q} & =\frac{2 T_{e}}{3 p \lambda_{m}},
\end{aligned}
$$

where $\omega_{m}^{*}$ and $\omega_{m}$ are the set and actual speeds; $T_{e}$, the 


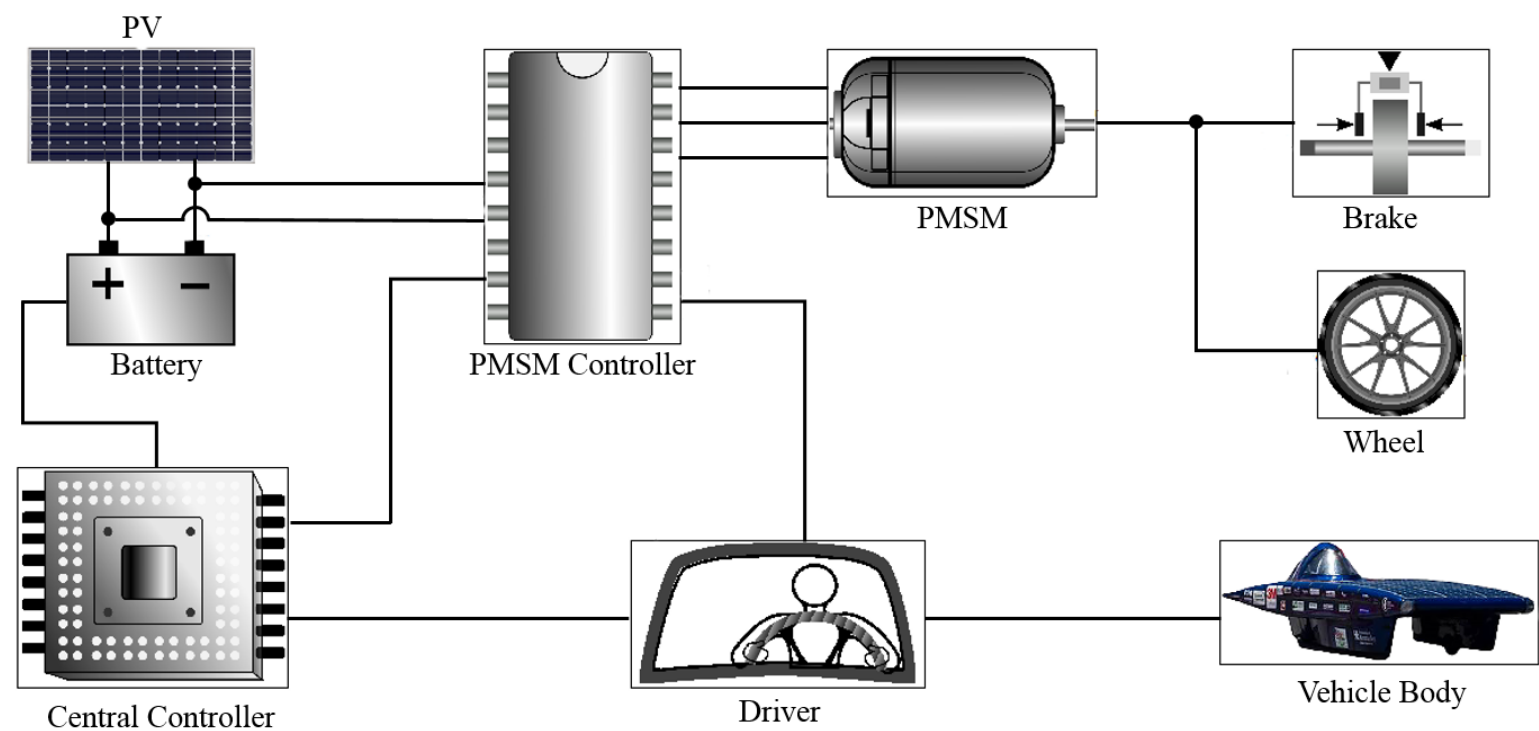

Figure 5. The model of a solar electric car in Simplorer, which can be viewed as another implementation of a series hybrid vehicle. The solar PV system includes an average model of a boost converter, which is used for maximum power point tracking.

desired electromagnetic torque; $\lambda_{m}$, the permanent magnet flux amplitude; $i_{q}$, the q-axis component of the current; $\omega_{m}$, the angular velocity of the rotor, and $p$, the number of pole pairs of the traction motor. The $d$ and $q$ components of the voltages are obtained by

$$
\begin{aligned}
& v_{d}=L_{d} \frac{d i_{d}}{d t}+R i_{d}-p L_{q} \omega_{m} i_{q}, \\
& v_{q}=p \lambda_{m} \omega_{m}+L_{q} \frac{d i_{q}}{d t}+R i_{q}+p L_{d} \omega_{m} i_{d},
\end{aligned}
$$

where $v_{d}$ and $v_{q}$ are the $q$ and $d$ axis voltages; $i_{d}$, the $\mathrm{d}$ axis current, zero in this case; $L_{q}$ and $L_{d}$, the $d$ and $q$ axis inductances and $R$, the stator winding's resistance. At steady state field orientation, the terminal voltage developed by the motor is given by,

$$
v_{s}=\sqrt{v_{d}^{2}+v_{q}^{2}}=\sqrt{\left(p \omega_{m} i_{q} L_{q}\right)^{2}+\left(p \lambda_{m} \omega_{m}+R i_{q}\right)^{2}} .
$$

The inverter switching and dynamics are neglected, and it is considered that the voltage calculated using (8) is applied to the motor. A simplified model for the battery, relating the voltage and state of charge which neglects temperature, selfdischarge, charge and discharge history is considered.

\section{SOLAR CAR MODELING}

The solar car, which can be considered as another implementation of a plug-in hybrid vehicle, with the battery charged by an on-board PV source, instead of an engine like in a conventional series hybrid electric vehicle (Fig. 5). In addition to the components of the electric vehicle of Fig. 2, it includes a solar panel and boost converter, which performs the functions of maximum power point tracking as well as raises the dc-bus voltage to the value required by the battery. A PV model based on the Norton equivalent circuit, as seen in Fig. 6 may

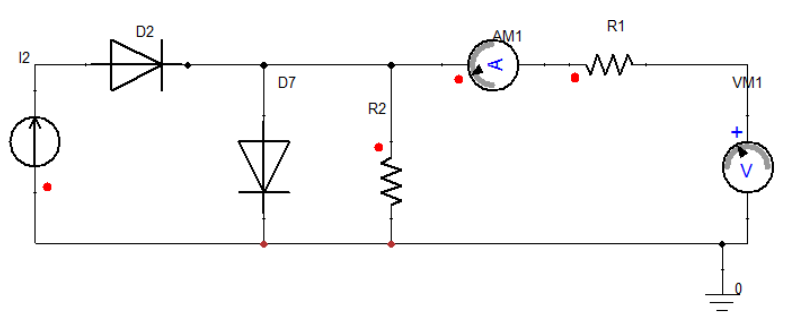

Figure 6. Implementation of the solar panel in ANSYS Simplorer including a current source and an exponential diode, D7.

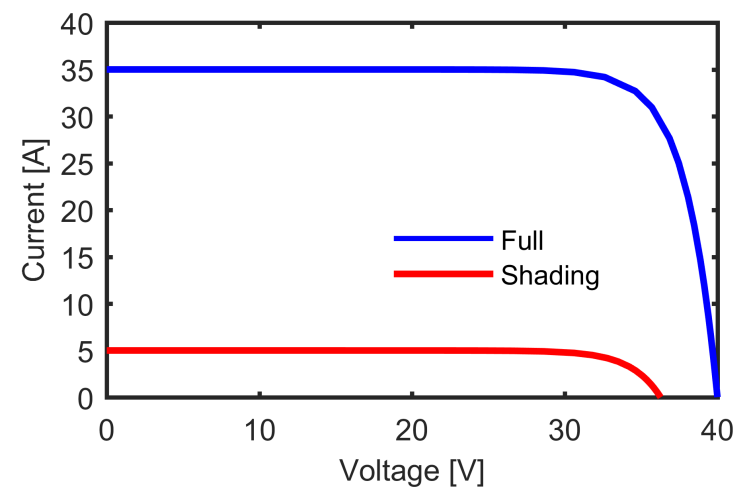

Figure 7. Characteristics of the solar panel used in the study under different conditions of irradiance.

be used, with the output current given by,

$$
I=I_{g}-I_{o}\left[e^{\left(\frac{V+I R_{s r}}{A n K T_{c} / q}\right)}-1\right]-\left(\frac{V+I R_{s r}}{R_{s h}}\right),
$$

where, I is the output current; $I_{g}$, the photo current; $I_{o}$, the saturation current; $A$, the ideality factor taken as 1.5 in this study; K, the Boltzmann constant; q, the electron charge; V, 


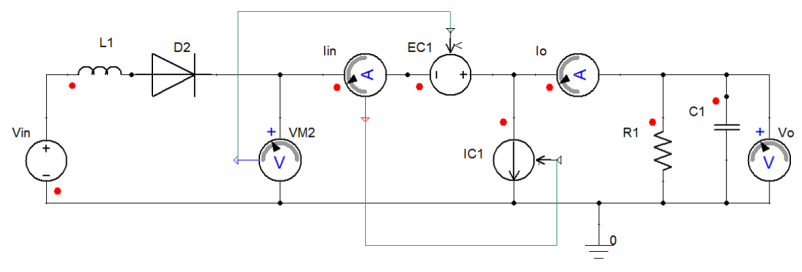

Figure 8. Implementation of an average model of the dc-dc boost converter in ANSYS simplorer.

Table I

PARAMETERS AND RATINGS OF COMPONENTS IN THE UK GATO DEL SOL V SOLAR CAR.

\begin{tabular}{lr}
\hline Car mass [lb] & 650 \\
Car maximum speed [mph] & 72 \\
Battery voltage [V] & $70-160$ \\
Battery capacity [Wh] & 4536 \\
Traction motor peak power [kW] & 7.5 \\
Solar panel maximum power [W] & 967 \\
Solar panel voltage [V] & 32 \\
\hline
\end{tabular}

the output voltage; $T_{c}$, the cell temperature; $n$, the number of cells in series; $R_{s h}$, the shunt resistance and $R_{s r}$, the series resistance. For known values of open circuit voltage, short circuit current and maximum power, the terms of equation (5) may be determined by a procedure described for example in [15]. The characteristics of the PV array considered in this study are illustrated in Fig. 7. An average model of the boost converter is implemented in ANSYS Simplorer (Fig. 8). The model includes controlled current (IC1) and voltage (EC1) sources, such that

$$
\begin{gathered}
E C 1=V_{i n} \frac{d}{1-d}, \\
I C 1=I_{i n} \times d,
\end{gathered}
$$

where, $V_{i n}$ is the input voltage to the boost converter; $d$, the duty cycle and $I_{i n}$, the input current. The circuit connection ensures that the output voltage and current are given as,

$$
\begin{gathered}
V_{o}=V_{i n}+E C 1=\frac{V_{i n}}{1-d}, \\
I_{o}=I_{i n}+I C 1=I_{i n}(1-d),
\end{gathered}
$$

in line with the steady state operation of the boost converter under continuous conduction. Maximum power point tracking is implemented by operating the boost converter at a duty cycle such that

$$
d=1-\frac{V_{m p}}{V_{b}},
$$

where, $V_{m p}$ is the maximum power point voltage of the PV panel, and $V_{b}$, the battery voltage. The maximum power point voltage is a function of the irradiance. This model neglects the dynamics of the MPPT controller, which is a reasonable assumption considering the long simulation times.

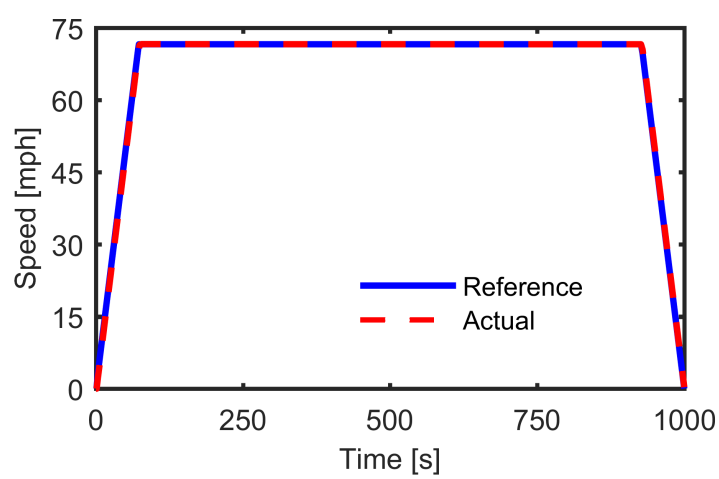

(a)

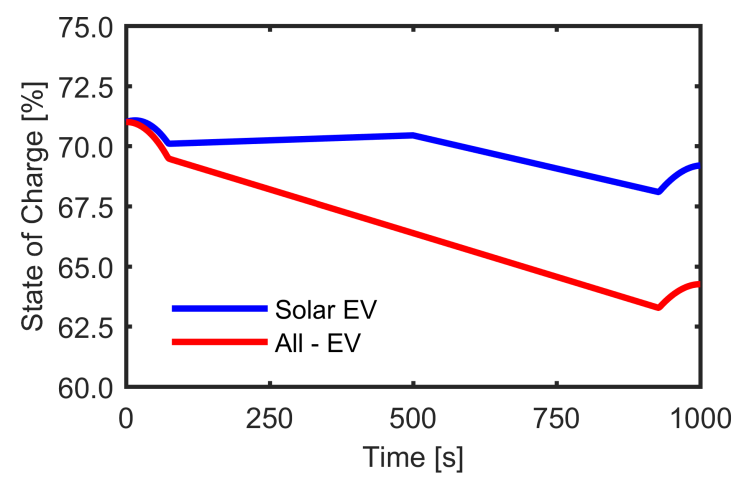

(b)

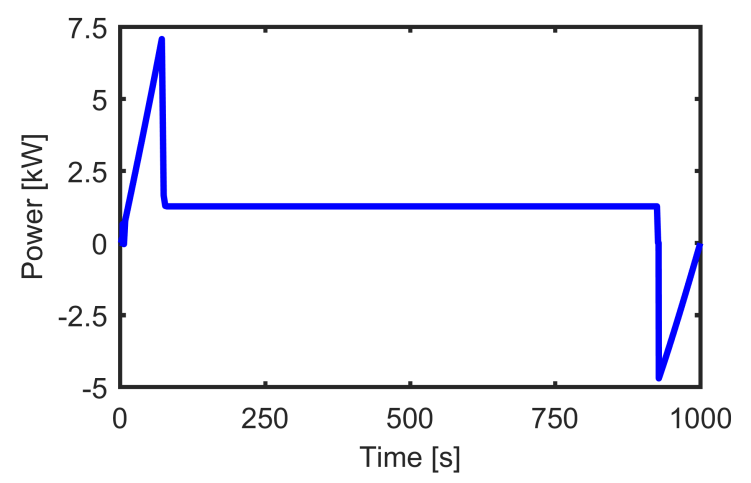

(c)

Figure 9. (a) Set and actual vehicle speeds over a driving cycle, and (b) The state of charge of the battery. In the all-EV case, the battery keeps discharging as it supplies power to the traction motor, while in the case of the solar powered EV, the battery discharges to a smaller extent (c) Power of the traction motor. Braking is accomplished entirely by the regeneration in this case.

\section{Results AND Discussion}

The system of Fig. 5, is solved using ANSYS Simplorer initially, for a simple driving cycle, in which the vehicle accelerates to and decelerates from a maximum speed of 72 mph. The vehicle cruises at this speed for approximately 900 seconds of the 1000 second driving cycle. The maximum acceleration is limited by the peak power rating of the traction motor. The system is simulated under conditions of varying irradiance, such that shading occurs when the vehicle is 


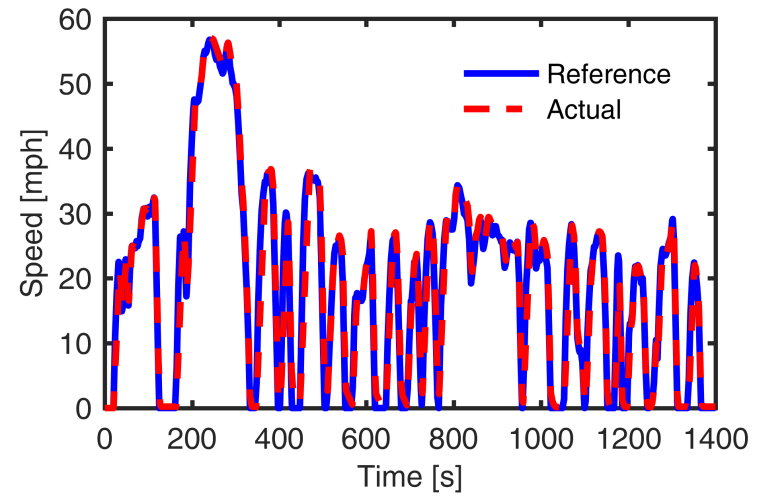

(a)

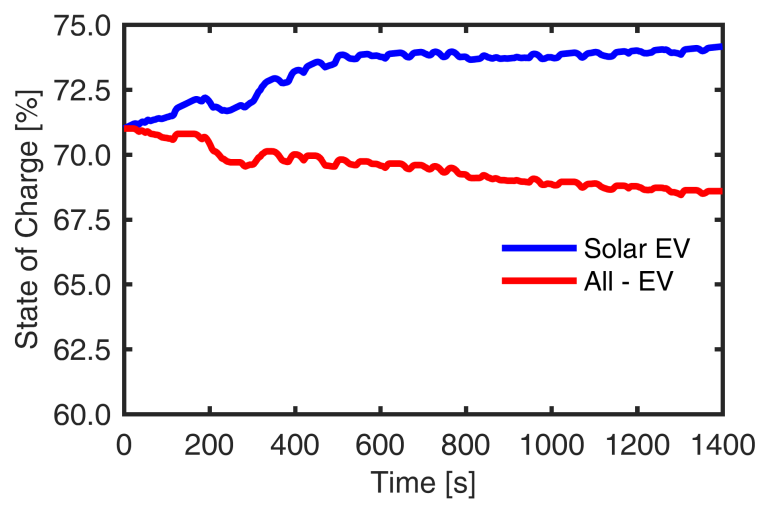

(b)

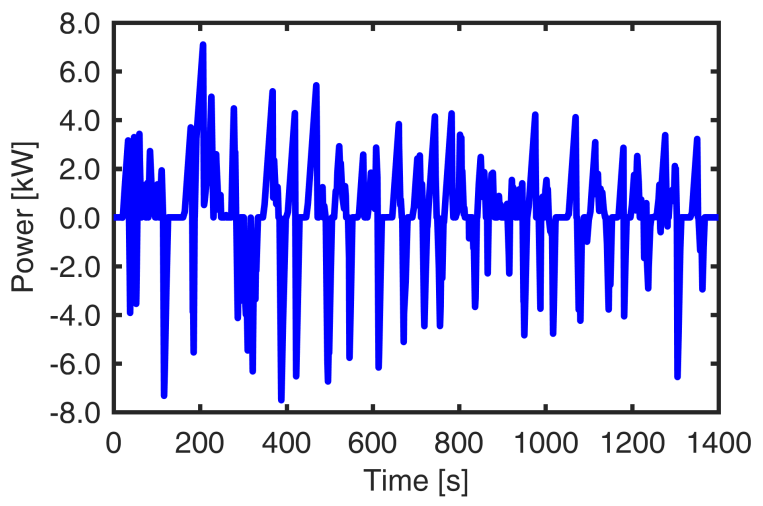

(c)

Figure 10. (a) Set and actual vehicle speeds over an urban driving cycle and (b) The state of charge of the battery. The vehicle's speed follows the set speed as long as the acceleration demands do not exceed the motor's rating.

cruising at $72 \mathrm{mph}$. Shading is simulated by changing the photocurrent of the solar cell in a step. In Fig. 9a, the vehicle's set and actual speeds are seen, and their equality confirms the successful operation of the EV model. The ratings of the different components are shown in Table I The state of charge for the battery is seen in Fig. 9b, and it reduces as the power is supplied to the traction motor, in the all-electric case. In the plug-in hybrid or solar EV configurations, the battery charges from the solar PV system. Braking is accomplished primarily

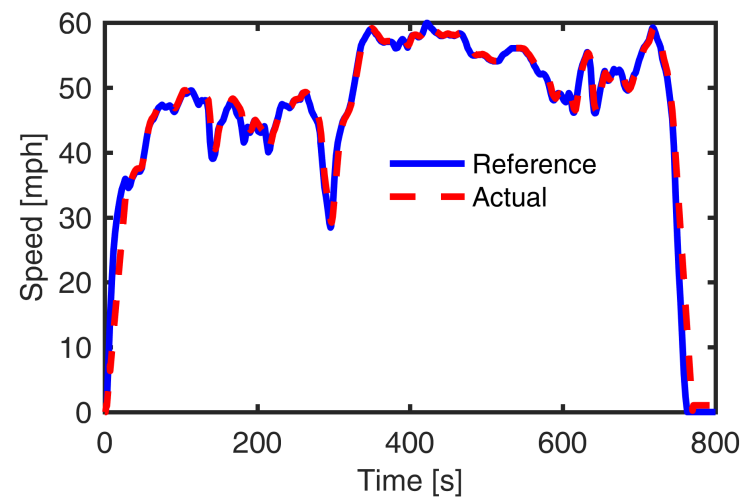

(a)

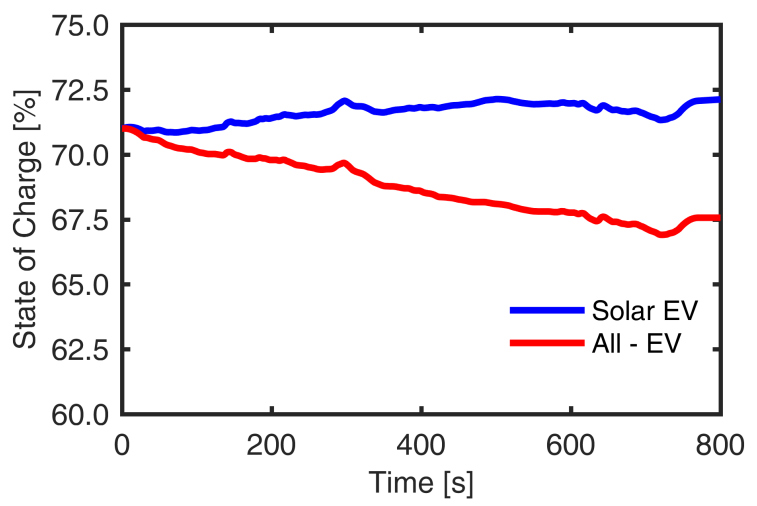

(b)

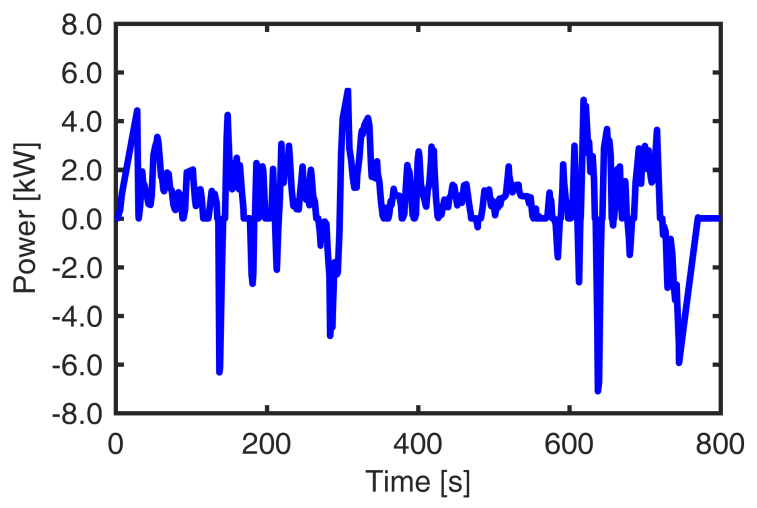

(c)

Figure 11. (a) Set and actual vehicle speeds over an EPA highway fuel economy driving cycle, and (b) The state of charge for the battery.

by regenerative means, as can be inferred from the power of the traction motor in Fig. 9c.

The system is tested for different types of driving cycles, the Urban Dynamometer Driving Schedule and Highway Fuel Economy Test from the EPA [16], and the results on set and actual vehicle speeds, as well as battery state of charge are seen in Fig. 10 and 12. The power of the motor is limited to the peak value of $7.5 \mathrm{~kW}$ as seen in Fig. 10c and 12c.

Switching models of the power electronics are developed, and the results for a specified operating condition are shown 


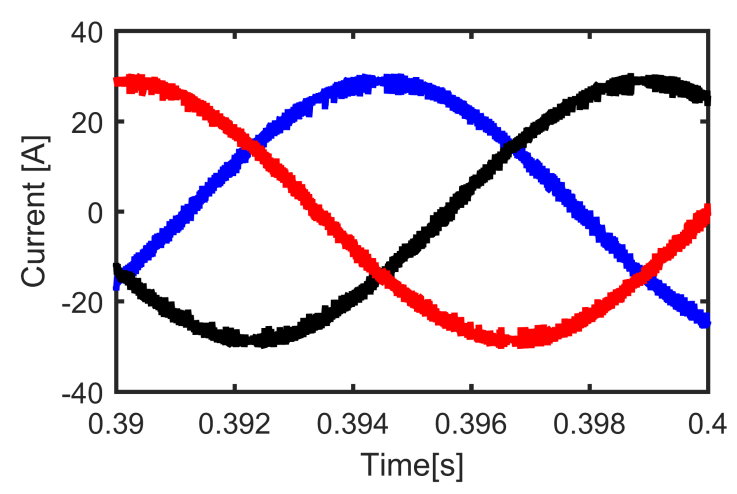

(a)

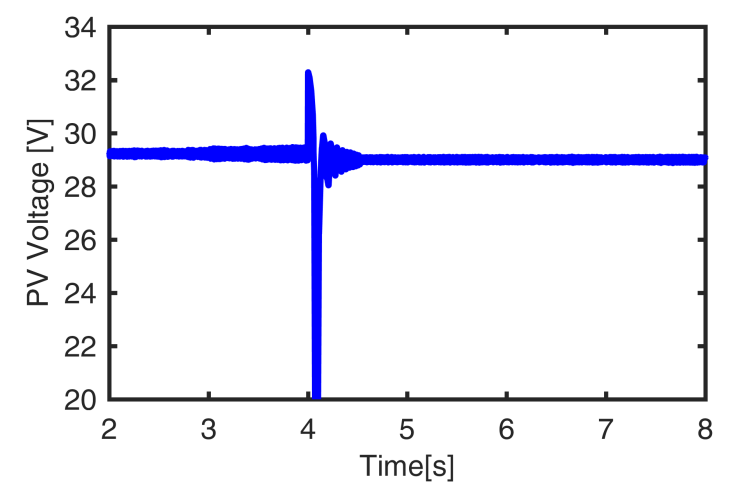

(b)

Figure 12. Switching models of the power electronics components at a particular operating point (a) Motor currents, (b) Voltage of the PV array. The boost converter maintains the voltage at maximum power point by changing the duty cycle. Results when a perturb and observe controller is employed are seen.

in Fig. 12a. The battery's voltage varies significantly with the state of charge, as seen in Table I, and a condition may occur when the inverter output voltage is not sufficient to drive the motor at the set speed. This could potentially lead to over-modulation of the inverter, leading to low frequency harmonics, mainly of the $5^{t h}, 7^{t h}, 11^{t h}$ and $13^{\text {th }}$ order in the current, and $6^{\text {th }}$ harmonic voltage ripple in the dc-bus, and under such conditions, the average models may not be sufficient. Maximum power point tracking is accomplished by the boost converter using a perturb and observe algorithm, and the solar panel's output voltage is seen when irradiance is changed in a step at $\mathrm{t}=4 \mathrm{~s}$ in Fig. $12 \mathrm{~b}$.

\section{CONCLUSION}

The multi-domain modeling of an in-wheel drive electric vehicle is exemplified for the Uninversity of Kentucky solar car, which includes solar panels, boost converter for maximum power point tracking and is driven by an axial flux permanent magnet synchronous motor. The modeling approach includes component level modeling of the vehicle, wheels, brake, engine, traction motor, battery and solar PV system using analytical equations. Average models for the inverter and boost converter are employed in order to accommodate for the large time constants of the mechanical system. The average models may be insufficient in case of non-ideal conditions such as reduced battery voltage, which might result in operation of the inverter in over-modulation leading to low frequency harmonics in the current, and in such cases switching models may be employed.

\section{ACKNOWLEDGMENT}

The authors are thankful to Aaraon Cramer, Narges Taran and Chris Heintz for their suggestions and technical contributions. The support of University of Kentucky, the L. Stanley Pigman endowment, and ANSYS, Inc. is gratefully acknowledged.

\section{REFERENCES}

[1] C. H. T. Lee, K. T. Chau, and L. Cao, "Development of reliable gearless motors for electric vehicles," IEEE Transactions on Magnetics, vol. 53 , no. 11, pp. 1-8, Nov 2017.

[2] A. Jaya, E. Wahjono, M. R. Rusli, E. Purwanto, F. D. Murdianto, and M. B. Fauziah, "Design and simulation of sensorless bldc motor drive using flux linkage increment based on the line-to-line bemf for electric vehicles," in 2017 International Electronics Symposium on Engineering Technology and Applications (IES-ETA), Sept 2017, pp. 161-166.

[3] V. T. Smundsson, M. Rezkalla, A. Zecchino, and M. Marinelli, "Aggregation of single-phase electric vehicles for frequency control provision based on unidirectional charging," in 2017 52nd International Universities Power Engineering Conference (UPEC), Aug 2017, pp. 1-6.

[4] A. Thingvad, C. Ziras, J. Hu, and M. Marinelli, "Assessing the energy content of system frequency and electric vehicle charging efficiency for ancillary service provision," in 2017 52nd International Universities Power Engineering Conference (UPEC), Aug 2017, pp. 1-6.

[5] J. Hu, H. Morais, T. Sousa, and M. Lind, "Electric vehicle fleet management in smart grids: A review of services, optimization and control aspects," Renewable and Sustainable Energy Reviews, vol. 56, pp. 1207-1226, 2016.

[6] B. H. Nguyen, D. Nguyen, V. D. Thanh, and C. T. Minh, "An emr of tire-road interaction based-on "magic formula" for modeling of electric vehicles," in 2015 IEEE Vehicle Power and Propulsion Conference (VPPC), Oct 2015, pp. 1-5.

[7] C. Wenge, B. Arendarski, K. Haensch, A. Naumann, and P. Komarnicki, "Electric vehicle simulation models for power system applications," in 2012 IEEE Power and Energy Society General Meeting, July 2012, pp. $1-6$.

[8] R. C. Hill, "Development of an introductory course on the modeling and control of advanced electric vehicles," in 2012 American Control Conference (ACC), June 2012, pp. 4470-4477.

[9] "Advsior - a powerful vehicle simulation tool," https://www.nrel.gov/ news/press/2002/2102_advisor_tool.html, accessed: 2018-01-02.

[10] "Autonomie," http://www.autonomie.net/, accessed: 2018-01-02.

[11] A. Emadi, Advanced Electric Drive Vehicles, ser. Energy, Power Electronics, and Machines. Taylor \& Francis, 2014. [Online]. Available: https://books.google.com/books?id=e-2sBAAAQBAJ

[12] N. Taran, V. Rallabandi, D. M. Ionel, and G. Heins, "A comparative study of coreless and conventional axial flux permanent magnet synchronous machines for low and high speed operation," in 2017 IEEE Energy Conversion Congress and Exposition (ECCE), Oct 2017, pp. 321-327.

[13] B. Novakovic, Y. Duan, M. G. Solveson, A. Nasiri, and D. M. Ionel, "From wind to the electric grid: Comprehensive modeling of wind turbine systems," IEEE Industry Applications Magazine, vol. 22, no. 5, pp. 73-84, Sept 2016.

[14] X. Liu, A. M. Cramer, and F. Pan, "Generalized average method for time-invariant modeling of inverters," IEEE Transactions on Circuits and Systems I: Regular Papers, vol. 64, no. 3, pp. 740-751, March 2017.

[15] H. Bellia, R. Youcef, and M. Fatima, "A detailed modeling of photovoltaic module using matlab," NRIAG Journal of Astronomy and Geophysics, vol. 3, no. 1, pp. 53 - 61, 2014. [Online]. Available: http://www.sciencedirect.com/science/article/pii/S2090997714000182

[16] "Dynamometer drive schedules," https://www.epa.gov/ vehicle-and-fuel-emissions-testing/dynamometer-drive-schedules, accessed: 2018-04-23. 